\title{
FEATURE-PLACING, LOCALIZABILITY, AND THE SEMANTICS OF EXISTENTIAL SENTENCES
}

\author{
Rachel Szekely, \\ The Graduate Center, CUNY ${ }^{1}$ \\ rszekely@gc.cuny.edu
}

\section{Introduction}

Many analyses of existential sentences have focused attention on determining which of its elements constitutes the logical subject and predicate, and this has proven to be a not uncontroversial topic of research. Some, from both syntactic and semantic points of view, have argued that there is a subject (cf. Williams 1994) others that it is a predicate (cf. Moro 1997). Similarly, some have argued that the associate NP is a logical subject, others that it is a predicate (Higginbotham 1987).

One logical possibility that has not (to my knowledge) been pursued in the linguistics literature is that these statements are not of the form subject-predicate, a possibility that has been taken up in the philosophical literature by P.F. Strawson $(1959)^{2}$. He claims that there are such statements and that their form is simpler than that of subject-predicate statements because it does not, and cannot, involve an expression that makes reference to an individual. Not involving reference to an individual, these sentences are therefore are made true by different means than a subject-predicate statement whose truth, in the simplest cases, depends on the denotation of the subject being a member of the denotation of the predicate. Of interest from the point of view of the present discussion is his claim that existential statements are examples of this kind of statement, which he calls a feature-placing statement. The truth of a statement of the form feature-placer requires that something with the set of features denoted by the associate NP exist at the location or coordinates expressed by the placer. In an existential sentence we can take the associate NP as the feature-denoting expression and the coda-XP as the placer.

(1) There is $\underline{\text { man }}_{\text {associate }} \mathrm{NP/feature-denoting} \mathrm{NP} \underline{\text { in the garden }}$ coda XP/placer.

\footnotetext{
${ }^{1}$ I would like to thank Robert Fiengo for his comments and discussion of the ideas presented here, as well as to the audiences at SuB 10 and the CUNY Syntax Supper.

${ }^{2}$ It seems to me that the thetic judgment of Brentano and Marty (and later Kuroda) is a related notion to the one I am about to introduce, not in the least because it assumes that subject-predicate is not the only kind of statement, and that existential sentences are of an alternate form. However, there are important differences between Strawson's feature-placing statement and the thetic judgement. A full discussion of this issue is impossible here, but I note that the sentence types that authors such as Kuroda (1972) claim to be used to make thetic judgments are of a substantially wider class than those being claimed here to be of the form feature-placer. For Kuroda (1972), generic sentences and (certain) copular sentences are assumed to be thetic, in addition to existential sentences. Both of these are outside the scope of what is being claimed here for feature-placing statements. See Ladusaw (1994) for another discussion of Brentano and Kuroda's work with respect to the semantics of existential sentences.
} 


\section{What are features?}

According to Strawson, features are those characteristics that make something a member of a kind, without the additional information required to re-identify a particular individual of the kind. He explains the difference between expressions that denote features and referential expressions by discussing two possible scenarios in what he calls "the naming game".

Playing the naming game may be compared with one of the earliest things which children do with language - when they utter the general name for a kind of thing in the presence of a thing of that kind, saying 'duck' when there is a duck, 'ball' when there is a ball, etc . . . But now what of the criteria of reidentification? Does the concept of the cat-feature include a basis for this? If so, what is the substance of the phrase 'a basis for criteria'? Is it not merely an attempt to persuade us that there is a difference, where there is none, between the concept of the cat-feature and the sortal universal, cat? This is the crucial question. I think the answer to it is as follows. The concept of cat-feature does indeed provide a basis for the idea of reidentification of particular cats. For that concept includes the idea of a characteristic shape, of a characteristic pattern for the occupation of space; and this idea leads naturally enough to that of a continuous path traced through space and time by such a characteristic pattern; and this idea in its turn provides the core of the idea of particular-identity for basic particulars. But this is not to say that the possession of the concept of the cat-feature entails the possession of this idea. Operating with the idea of reidentifiable particular cats, we distinguish between the case in which a particular cat appears, departs and reappears, and the case in which a particular cat appears and departs and a different cat appears. But one could play the naming game without making this distinction. Someone playing the naming game can correctly say 'More cat' or 'Cat again' in both cases; but someone operating with the idea of particular cats would be in error if he said 'Another cat' in the first case or 'The same cat again' in the second. The decisive conceptual step to cat-particulars is taken when the case of 'more cat' or 'cat again' is subdivided into the case of 'another cat' and the case of 'the same cat again'. [Strawson (1959) p. 206-208]

Given this description, it is possible to understand in what sense Strawson considers featuredenoting expressions and feature-placing statements to be different and also simpler than those that contain identifying reference to an individual. The claim is that making identifying reference to an individual requires something above and beyond registering that an individual is an example of a kind. By examining some well-known properties of the associate NP in existential sentences (as will be done below), the correspondence between the expressions allowed as the associate NP and Strawson's notion of feature will become clear and will allow me to further define and formalize the notions of feature and feature-placing.

\subsection{The definiteness effect}

It is a well-known property of existential sentences that the associate NP may not be a definite $\mathrm{NP}$, a fact widely discussed in the literature under the heading of the definiteness effect ${ }^{3}$.

\footnotetext{
3 I will not discuss the so-called list existentials here (e.g. A: What is there in the fridge for dinner? B: Well, there's the leftover beef stroganoff), or other environments where a definite NP is fine in the existential construction. Some of these will require another treatment. Other environments seem to be cases (like superlatives) where in spite of the definite morphology an indefinite interpretation seems to obtain (e.g. There's the cutest little bunny in the garden.). See Abott (1997), Rando and Napoli (1978), among others, for discussion.
} 
(2) There is a man in the garden.

(3) *There is the man/John/the king of France in the garden.

If we consider the existential sentence to disallow (in the associate position) an expression that makes identifying reference to an individual, the restriction on definite NPs in this position becomes clearer. The following discussion will provide further support for this understanding of the definiteness effect and begin to formalize a constraint that disallows these DPs.

\subsection{Heim (1987): Questions from existential sentences}

Based on the unavailability of pronouns in existential sentences, Heim (1987) proposes that individual variables count as strong NPs (i.e., they trigger the definiteness effect) and proposes that the following constraint is operative in existential sentences:

(4) *There is you in the garden.

(5) *There-be $x$, when $x$ is an individual variable.

This constraint is in line with what has been proposed here with regards to the ban on expressions that introduce individuals into the discourse, and her supporting evidence also provides support for that claim. This evidence concerns wh-questions, constructions that involve movement of the wh-operator or entire wh-phrase; this movement has been held to leave behind a variable in the position of the moved element at some level of representation. Assuming that individual variables are excluded from there-contexts, how can we explain the grammaticality of the following example? (Heim discusses the full range of $w h$-phrases; I will limit my discussion to what for brevity.)

(6) What is there in Austin?

Of the wh-phrases one might examine, what is certainly one that is likely to involve an individual variable in the position of the moved element. After all, this is the case in other what-questions, like what are you holding? The content of such a question might be represented as the $x$ such that you are holding $x$. Is this the case for the what-question in the existential case above? Heim suggests that it is not, and I agree. In the case above, one suitable answer could be:

(7) There are lots of restaurants and places to hear live music.

A person using the question above need not be looking for a particular item(s). After all, there are many things in Austin, so the person is probably not looking for the thing that there is in Austin. Instead, they are interested in the kinds of things that there are ${ }^{4}$. For this reason, Heim argues that here what should not be analyzed as which $x$ but as such an $x$, that is, the variable left behind would not be ranging over individuals but over kinds. Following the treatment of such by Carlson (1977), she suggests that such an $N$ is interpreted in wh-questions as of kind $x$. That is, the existential sentence what is there in Austin corresponds to something like:

(8) There are/is such stuff/such things/such a thing in Austin.

The interpretation of $w h$-questions provides evidence in support of an analysis that takes the definiteness effect to be explained as a ban on expressions that introduce individuals in the associate NP position of existential sentences. Importantly, it also aligns the behavior and interpretation of the associate NP with that of kinds. Before moving to formalize these notions, consider an example that makes a similar point: one-anaphora.

\footnotetext{
${ }^{4}$ Again, I am abstracting away from the list reading, another possible answer to the question what is there in Austin? A list-reading response could be something like the following: There's that movie theater where they let you bring in beer, the restaurant where we met your cousin, etc.
} 


\subsection{One-anaphora}

As discussed by Heim (1987), bound variable anaphora is not allowed in existential sentences. One kind of anaphora that works in these sentences, however, is one-anaphora. As is well-known, one-anaphora makes a connection not to the entire NP but only the noun head and optionally its modifiers. For example:

(9) Mary has a green shirt and Jane has one, too.

Here, one is substituting for the N' and not the entire NP, that is, Jane is understood to have a shirt of the same kind, namely a green one, and not the same shirt as Mary. One-anaphora is thus not a connection with a referential NP. As mentioned, unlike bound variable anaphora, one-anaphora is possible in existential sentences:

There is a man asleep and there is one sick, too.

*There is a man asleep and there is he/him sick, too.

The fact that one-anaphora is available in there-sentences supports the idea that the associate NP is feature-denoting, where features are like kinds, in a way to be made precise.

\subsection{Quantification and the strong-weak distinction}

Milsark (1974) observed that cardinal and strong quantificational NPs differ in their ability to be licensed in an existential sentence, cardinal quantifiers being licensed while strong quantifiers are not. Examples like (14), however, which have also been noted in the literature, show that the ban on strong quantificational NPs is not absolute.

There are three/few/many/several/some cats in the garden.

*There is/are most/every/each cat(s) in the garden.

There is every kind of wine at this shop.

In order to understand the difference between (13) and (14) let us first discuss the case of (12) with respect to the idea of feature-placing. In the feature-placing statement, I claim that the contribution of the cardinal quantifier is to indicate how many times the features denoted by the NP must be (successfully) placed in that location in order to satisfy the truth conditions of the sentence, i.e., there are several cats in the garden is true only if there are several things with the cat-feature(s) in the garden. Now, what of the ungrammaticality of (13)? On its usual interpretation the quantifier every ranges over the set of individuals corresponding to the head noun, and its truth conditions are fulfilled if every individual $\mathrm{N}$ in the set is a member of the denotation of the predicate; in feature-placing terms, one might say the truth conditions contributed by every are satisfied if every member of the set was placed at the location specified by the placer. Remember, however, that based on the definiteness-effect facts as well as those observed for $w h$-questions by Heim (1987), it has been proposed that the NP in existential sentences does not introduce individuals into the discourse, only kinds. Therefore, a strong quantificational determiner that ranges over individuals, for example, the determiner that would take (13) to mean every individual cat, is therefore not grammatical in this position. A quantificational determiner that ranges over not individuals but kinds, however, as in (11), is fine. Note also that to the extent that the NP in (13) can be interpreted as every kind of cat, it is also felicitous.

The present analysis, then, leads one to the conclusion that the strong-weak distinction as originally formulated should be recast in terms of individuals and kinds. Those expressions that are allowable in the associate NP position of an existential sentence denote, or quantify over, kinds. Those that are not denote, or quantify over, individuals. Theoretically speaking, this is a desideratum; it allows us to provide a uniform account of why both definite and 
strong quantificational NPs (in the relevant interpretations) are disallowed in existential sentences.

\subsection{Presupposition}

Before moving on, it is necessary to address another influential account of the strong-weak distinction in existential sentences that relies on presupposition. Zucchi (1995) points out that the class of NPs that is banned from existential sentences coincides with the class of NPs that are presuppositional. Therefore, the definiteness effect in existential sentences can be captured by positing a felicity condition that requires the NP associate to be nonpresuppositional. This requirement is also in line with the fact that the existential sentence is an assertion of the existence and hence incompatible with the presupposition of existence.

This approach in many ways is in line with the semantics of the associate NP that will proposed here, in that the class of NPs that denote features seems to coincide with the class which is not presuppositional. One problem for a purely presuppositional approach to the strong-weak distinction in existential sentences, however, is the existence of cases, like (14), in which "presuppositional" determiners are fine in this context. For this reason, an approach that takes the strong-weak distinction to be a result not of a condition on the presuppositional qualities of NP but on its semantic form may be preferred.

\subsection{Formalization of features and kinds}

So far it has been claimed that the position of the associate NP in existential sentences is reserved for nominal expressions that are feature-denoting and therefore do not introduce individuals. This can be stated formally as follows: The requirement for a feature-denoting $\mathrm{NP}$ equates to the requirement for a set-denoting NP, i.e., an expression of type $\langle\mathrm{e}, \mathrm{t}\rangle$, where the set contains features, not individuals (i.e., although set-denoting, they are not properties, the prototypical predicate expression). As shown above, this move is in line with the interpretation of NPs that can appear in this position, and allows for a reformulation of the strong-weak distinction. The idea that the associate NP is set-denoting has also been proposed and defended by McNally (1998) and Landman (2004).

\section{Is this NP in a predicate position? Is it a predicate?}

Having claimed that the associate NP is a set-denoting expression, the question now arises as to whether it should also be considered a predicate NP. Unlike Higginbotham (1987), but in line with Landman (2004), I do not take this expression, although set-denoting, to be a predicate. The reason that I do not is because unlike Higginbotham (1987), who takes the expletive there to be a subject, I do not take this expression to be associated with a subject (and nor do I take it to be the subject of some higher predicate, as in McNally 1998). This hypothesis is in line with Strawson's claim that the sentence is not of the form subjectpredicate, and in fact, Landman (2004) provides evidence against the claim that these are predicates. As he points out, although the associate NP observes many of the same restrictions that a predicate NP does (ban on quantificational NPs, the narrow scope restriction), definite NPs, which are licensed in predicate position, are banned in the position of the associate NP. Furthermore, I take it that the associate NP denotes a set of features, not a set of individuals, which is what a predicate/property denotes. The NP associate is thus a kind-denoting NP, with kind-denoting in this account being equivalent to set-denoting where the set is a set of features.

\section{Summary:}

- The associate NP is an expression of type <e,t>, i.e., set-denoting

- It denotes a set of features (not individuals) 
- The associate may not presuppose the existence of individuals (vs. kinds)

- The associate is not a predicate (not a subject, either)

- The strong-weak distinction can be reformulated as a distinction between individuals and kinds

\section{What are placers?}

The second part of the equation in a feature-placing statement is the placer. I take the expressions that are allowed in the coda position, PPs like in the garden and APs like sick, to be placers, and take the truth of a feature-placing statement to depend on whether there is something with feature denoted by the NP is at the coordinates denoted by the placer.

At this point, however, it is necessary to address the fact that an existential sentence can perfectly well stand with no coda XP, as in sentences like there is a Santa Claus. In such cases, I take it that a default location is interpreted: either the universe (or world, depending on the semantics that is to be adopted) or in the contextually salient situation or location. In the sentence there is a Santa Claus, for example, the location defaults to the actual world. In the sentence there is a problem, the location seems to default to the salient situation. There is a Santa Claus.

In the following section I will discuss how the idea of placing can help us understand the restrictions on the items that occupy coda position.

\subsection{The predicate restriction}

The predicate restriction (or stage-level / individual-level distinction) that is found in this position then depends, on this account, on whether the item can be successfully used as a placer. There is a man in the garden. *There is a man fat.

predicate restriction

Of course, some of the items (PPs) we find in this position are more obviously locational than others (APs). Although other options might be pursued, I will argue here that there is reason to believe that, although it is more obvious in the PP cases than in the AP cases, the expressions in the coda-XP position are, in a relevant sense, items that can locate other items, and thus can be considered placers.

It seems that one property of things that are coordinate denoting is that they themselves can be located with respect to another location. This property, which I will call localizability, seems to distinguish among the predicates that are and are not felicitous as the coda in existential sentences. I formalize these notions below:

(19) A predicate can localize something if and only if the property it denotes is localizable.

(i.e., a thing which localizes something must itself be localizable)

Only predicates that are localizable are licensed in the coda of the existential construction.

There is some evidence that the codas allowed in the existential construction are localizable. For example: 
Predicates that are felicitous in the coda allow for further spatial modification

There is a man sick in the next room.

There is a man available at the Phoenix office/on the $4^{\text {th }}$ week of every month.

*There is a wall red in certain patches.

*There is a man tall in the garden.

Similarly, predicates that are felicitous in the coda naturally allow for where questions

(25) There is a man sick.

(26) Where is there a man sick?

(27) There is a man available.

(28) Where is there a man available?

(29) *There is a wall red.

(30) *Where is there a wall red?

(31) *There is a man tall.

(32) *Where is there a man tall?

As a further example of the ability of a predicate that locates to be localized, notice the differing behavior of the names of the properties denoted by certain localizing predicates in the associate NP position.

There is a man sick.

There is a man available.

*There is a wall red.

The wall is red.

*There is a man tall.
$>$ There is (a) sickness in New York.

$>$ There is availability on Sunday.

$>$ There is red(ness) on the wall.

$=$ There is a patch/spot of red on the wall.

$>$ *There is tallness in Sweden.

While the correspondence between properties (e.g. tall) and their names (e.g. tallness) is admittedly not always precise (cf. Chomsky 1970), the above are examples where names of the properties denoted by predicates that are licit in the coda of existential sentences that may be localized as the associate NP in an existential sentence, whereas names of properties that are illicit in the coda either may not stand as the associate or else must be interpreted as spatially defined.

Also note that the interpretation of the predicate sick which is available in (36) is the sense that may be localized, as in John is sick at home with the flu. Its other interpretation, as in *John is sick in the head at home, is not available. It is only the first interpretation that may be localized and is able to locate the feature denoted by the NP associate.

Finally, whether or not the particular formulation of location-sensitivity given above is accepted, the idea that there is a locative element to existential sentences has been advanced by authors starting at least with Lyons (1967), Kuno (1971), Clark (1978) and Freeze (1992). In this sense, an approach that defines the coda restriction in terms of an ability to be spatially localized also provides a way of characterizing this locative content (without recourse to the notion that the expletive subject itself is locational).

\section{Sentential semantics of feature-placing sentences}

I have suggested so far that that assertion in a feature-placing sentence is accomplished by some combination of a set-denoting NP and a syntactically optional (but I argue semantically necessary) coordinate-denoting expression. Therefore, the logical form of these sentences would be something like:

\section{[feature position]}

This form is different in important respects from the usual form assumed for existential sentences in that it assumes neither existential quantification over an individual nor an 
existential predicate (there-be). Furthermore, the logical form consists of a single clause, not three. This will become important in considering the scope facts for existential sentences.

However, if the associate NP in the existential construction does not introduce individuals into the discourse, and the logical form of existential sentences contains no existential quantification or no existential predicate how does their existential import arise? I would like to suggest that the existential import of these sentences arises from the content of their truth conditions rather than the content of their logical form. So, instead of the logical form containing an existential quantifier or existential predicate, the truth conditions that require that an item with a set of features at a location exists. These statements are made true or false, then, by virtue of the required set of features existing at the coordinates denoted by the coda. Below the two different proposals for the semantics of these sentences are compared:

\section{Feature-placing analysis}

A sentence of the form [ $\mathrm{f} p]$ is true iff there is an $\mathrm{x}$ that has $\mathrm{f}$ at $\mathrm{p}$.

\section{"Standard"analysis}

A sentence of the form [there exists an $\mathrm{x}$ ], [ $\mathrm{x}$ is a man] and [ $\mathrm{x}$ is in the garden] is true iff there is an $\mathrm{x}, \mathrm{x}$ is a man, and $\mathrm{x}$ is in the garden.

In the proposed semantics, then, there is an asymmetry between the logical form of the sentence and the truth conditional content of the statement. The existential import is located in the truth conditions and not the logical form (whereas in the traditional view, these two are symmetrical: both sides contain an existential clause). From the point of view of the interpretation of existential sentences, namely, that they assert existence and do not presuppose it, and in concert with the presupposition facts mentioned above, I would argue that moving the requirement for existence into the truth conditional content seems to better reflect the interpretation of these sentences, which do not imply existence as part of their meaning but assert it on the occasion of their use.

In fact, adopting the analysis outlined above for existential sentences enables us to account for some of their notable properties beyond those already discussed.

\subsection{Copular sentence vs. existential sentences}

The similarities between copular and existential sentences have long been noted, with some arguing that the form of the existential is transformationally related to the copular sentence.

A man is in the garden.

There is a man in the garden.

Given what I have said about feature-placing sentences in opposition to subject-predicate sentences the analysis predicts, however, that these sentences are of a different logical form, even if they are truth-conditionally equivalent (and I agree that they are). The copular sentence is of the form subject-predicate while the existential sentence is not. What evidence is there in support of the position that their logical forms differ?

In order to bring out the differences between copular sentences with indefinite NP subjects and existential sentences, let us look at some well-known scope facts: The associate NP in existential sentences takes narrow scope with respect to operators such as negation. This is not the case in copular sentences. The copular sentence below, for example, when negated, can be interpreted as saying that a certain winged horse is not in the garden. This is not the case in the existential sentence and suggests that there is an existential quantifier present in the logical form of the one (the copular sentence) and not in the other (the existential sentence).

(43) There is a winged horse in the garden. 
(44) There isn't a winged horse in the garden.

(45) A winged horse is in the garden.

(46) A winged horse isn't in the garden.

These facts also provide support for the current analysis of the logical form of these sentences, which is mono-clausal, against their usual analysis, which takes them to be tripartite structures. Given a tripartite structure, it is not clear why only widest scope is possible for negation. Given a single clause, there is not another option.

There is not a winged horse in the garden.

$\neg[\mathbf{f}$ winged horse $\mathbf{p}$ in the garden]

$\neg[$ there exists an $\mathrm{x}],\left(*_{\neg}\right)\left[\mathrm{x}\right.$ is a winged horse] and $\left(*_{\neg}\right)[\mathrm{x}$ is in the garden]

$=$ It is not the case that there is a winged horse in the garden.

$\neq$ There is something such that it is not a winged horse in the garden.

$\neq$ There is a winged horse such that it is not in the garden.

\subsection{More anaphora ${ }^{5}$}

The above discussion of Heim (1987) regarding the unavailability of pronouns in existential sentences can also be extended to accommodate sentences like the following:

There is a man and his wife in the garden.

As in the case of wh-questions discussed above, an account of the pronominal anaphora in the sentence above does not demand an individual variable, but may be accomplished with a variable that ranges over sets of features, i.e., kinds ${ }^{6}$. After all, the sentence above does not refer to a specific man and his wife; the truth conditions merely require that a man and his wife be found in the garden.

For another case of anaphoric connection, consider the following examples from Partee:

I have lost ten marbles and found all but one. It might be under the couch. I have lost ten marbles and found nine of them. \#It might be under the couch.

The sentence in (52) illustrates that conversational salience or logical inference is not enough to guarantee the possibility of pronominal reference. The expression the pronoun is anaphoric to must be available in the content of the discourse. Now, given the fact that the present approach claims no individuals are introduced into the discourse in the logical form of existential sentences, what can be said about the pronominal reference in the following sentences?

There is a man in the garden. He is wearing pajamas.

Whereas I am claiming that the logical form of existential sentences does not introduce individuals into the discourse, the truth conditions of an existential sentence like that in (54) require that a man exist at the coordinates expressed by the placer. It is to this man that the pronoun refers. This cannot technically, then, be considered a case of anaphora. Instead, we must assume that the pronoun above is deictic to the individual required by the truth conditions of the existential sentence.

There is some reason to believe that this approach to the pronominal reference above is correct. Take, for example the form of denials of existential statements:

\footnotetext{
${ }^{5}$ I would like to thank Harriet Taber for first bringing the facts in (50) to my attention as well as Daniel Rothschild, in the audience at SuB 10, for making me aware of the relevance of the Partee facts.

${ }^{6}$ It need not necessarily be assumed that anaphoric connection is accomplished via binding: cf. Fiengo and May 1994 for arguments against the binding approach to anaphora.
} 
There is a man in the garden. \#No, he's not. (=No, there isn't a man in the garden)

As (54-57) show, although a statement of the form feature-placer may be felicitously followed by a statement containing a pronominal subject that takes as its referent the individual required to satisfy the truth conditions of a feature-placing statement, it is not felicitous to follow a feature-placing statement with a sentence that contains the same pronominal subject and an a denial of the original statement. This is because in order to deny the original statement you must take its truth conditions to be unfulfilled; the denial of the original statement, therefore, asserts that the pronoun has no referent (at that location). In (57), however, only a partial denial is stated: the existence of the referent of the pronoun is not in question, only his location. Thus, pronominal reference is felicitous in such a case.

\section{Concluding remarks}

In conclusion, let us return briefly to the debate about which constituent is the existential sentence constitutes the proper subject or predicate. By adopting an account of existential sentences in terms of feature-placing, it is possible to supercede such discussion while providing a principled (and straightforward) reason for these sentences' special surface form, that is, for why they appear with an expletive subject.

\section{References}

Abbott, B.: 1997, Definiteness and existentials. Language 73:1, 103-108.

Carlson, G.: 1977, A Unified Analysis of the English Bare Plural. Linguistics and Philosophy. 1: 413-457.

Diesing, M.: 1992, Indefinites. Cambridge: MIT Press.

Diesing, M.: 1988, The Syntactic Roots of Semantic Partition. Dissertation, UMass Amherst.

Dobrovie-Sorin, C.: 1998, Types of Predicates and the Representation of Existential Readings, Proceedings of SALT (1997), Cornell University

Fernald, T.: 1994, On the Non-Uniformity of the Individual- and Stage-level Effects. Dissertation, University of California, Santa Cruz.

Fiengo. R. and R. May: 1994, Indices and Identity. MIT Press.

Heim, I.: 1987, Where does the definiteness restriction apply? in Reuland, E. \& ter Meulen, A.: 1987, (eds.), The Representation of (In)definiteness, Cambridge, Mass.: MIT Press, pp. 21-42.

Higginbotham, J. \& G. Ramchand.: 1997, The Stage-Level/Individual-Level Distinction and the Mapping Hypothesis, in Oxford University Working Papers in Linguistics, Philology \& Phonetics 2: 53-83.

Higginbotham, J.: 1987, Indefiniteness and Predication, in Reuland, E. \& ter Meulen, A. 1987., (eds.), The Representation of (In)definiteness, Cambridge, Mass.: MIT Press, pp. 43-70. 
Keenan, E.: 1987, A Semantic Definition of "Indefinite NP, in Reuland, E. \& ter Meulen, A. 1987., (eds.), The Representation of (In)definiteness, Cambridge, Mass.: MIT Press, pp. 286-317.

Ladusaw, W.: 1994, Thetic and Categorial, Stage and Individual, Weak and Strong, in Proceedings of SALT IV, eds. Mandy Harvey and Lynn Santelmann. CLC Publications.

Kratzer, A.: 1995, Stage Level and Individual Level Predicates, in G. Carlson \&F.J. Pelletier (eds.): The Generic Book. Chicago (The University of Chicago Press), 125-175.

Landman, F.: 2004, Indefinites and the Type of Sets. London: Blackwell.

Milsark, G.: 1974, Existential Sentences in English. Dissertation, MIT.

McNally, L.: 1993, Adjunct Predicates and the Individual/Stage Distinction, in Proceedings of WCCFL 12.

McNally, L.: 1998a, Stativity and Theticity, in S. Rothstein (ed.) Events and Grammar, Kluwer, Dordrecht, 293-307.

McNally, L.: 1998b, Existential Sentences without Existential Quantification, Linguistics and Philosophy 21, 353-392.

Moore, G.E.: 1936, Is existence a predicate? in G.E. Moore: Selected Writings, ed. Thomas Baldwin. New York: Routledge, p. 134-146.

Moro, A.: 1997, The Raising of Predicates: Predicative Noun Phrases and the Theory of Clause Structure, Cambridge UP, Cambridge New York Melbourne.

Quine, W.V.: 1948, On what there is, in From a Logical Point of View. London: Oxford University Press, p. 1-19.

Rando, E. and D. Napoli.: 1978, Definites in there-sentences, Language 54: 300-13.

Strawson, P.F.: 1971, The Logico-Linguistic Papers. London: Methuen and Co., Ltd.

Strawson, P.F.: 1959, Individuals. London: Methuen and Co., Ltd. 